\title{
Visual signal detection and the locus of foreperiod effects*
}

\author{
RAYMOND KLEIN $\dagger$ and BETH KERR \\ University of Oregon, Eugene, Oregon 97403
}

\begin{abstract}
The effect of alertness on S's sensitivity to external signals was determined by varying the foreperiod in a visual signal detection task. Discriminability increased with increasing foreperiods up to an optimal foreperiod, beyond which it decreased slightly. This pattern of results parallels closely that of many foreperiod studies in which reaction time was the dependent variable. Because no speeded response was required in this signal detection task, it was concluded that alertness must be affecting an information processing stage prior to those associated with responding. Other evidence indicates that alertness does not affect sensory stages either. Alertness, by elimination, must be affecting the operation of a central stage. Posner's view of alertness which implicates the central stages is discussed.
\end{abstract}

Reaction time to a signal requiring a rapid response is decreased when a warning signal precedes the reaction signal. The time course of this alteration in performance has been carefully studied (Bertelson, 1967; Bertelson \& Tisseyre, 1968, 1969; Klemmer, 1956; Posner, Klein, Summers, \& Buggie, 1973). ${ }^{1}$ It is generally found that as the foreperiod (interval between the warning and reaction signals) increases, reaction time decreases until some optimal foreperiod is reached, beyond which reaction time remains the same, or increases slightly. Several physiological parameters also change during the foreperiod. The presentation of a warning signal results in alpha blocking, and is followed by cardiac deceleration and a slow negative drift in EEG (CNV) (Lansing, Schwartz, \& Lindsley, 1959; Tecce, 1972; Webb \& Obrist, 1970). Although correlations between single parameters and performance are often small (Rebert \& Tecce, in press), it is generally assumed that the constellation of physiological changes is closely related to the alteration in performance. This change of state of the organism which follows a warning signal has been called preparation by some and alertness by others. In this paper it will be referred to as phasic alertness (Posner, 1974) to distinguish it from more gradual changes which may have different psychological and physiological consequences.

We view the organism as an information processing system. The changes in performance which accompany phasic alertness must be due to a modification of some stage (or stages) in the information processing sequence between stimulus and response. An important question concerns the locus and form of the effect: What stage is affected by phasic alertness, and how? In broad terms, phasic alertness may affect sensory, central, or motor

* This research was supported in part by Grant OEG-0-72-0717 from the Office of Education to M. I. Posner and NIE Grant NE-G-00-3-0144 and NIMH Grant MH 17958 to W. A. Wickelgren. We would like to thank Drs. Posner, Wickelgren, and $S$. W. Keele for suggestions and comments on earlier drafts of this manuscript.

tRequests for reprints should be sent to Raymond Klein, Department of Psychology, University of Oregon, Eugene, Oregon 97403. stages. For example, it may affect the rate of buildup of information about the stimulus (sensory); it may affect the rate of motor response (motor); or it may affect the decision mechanism (central). These three alternatives will be evaluated below.

There is evidence from three sources which indicates that phasic alertness does not affect the rate of buildup of information about the stimulus. (1) Several studies have covaried stimulus intensity and foreperiod duration in a reaction time situation. As long as neither extremely weak or strong stimuli are considered, ${ }^{2}$ foreperiod duration and stimulus intensity have additive effects (Botwinick, 1969; Botwinick \& Storandt, 1972; Raab, Fehrer, \& Hershenson, 1961; Bernstein, Chu, Briggs, \& Schurman, 1973). This result suggests that these two variables affect different processing stages (Sternberg, 1969). Stimulus intensity is generally assumed to affect the rate of buildup of information about the stimulus. Therefore, phasic alertness probably does not. (2) Posner and Boies (1971) reached a similar conclusion. They varied both the interval between two letters in a matching task and the foreperiod duration. The improvement in reaction time that occurred when one letter preceded the other (as compared to a simultaneous condition) was the same regardless of the level of alertness. This improvement is due to extraction of information about the first stimulus (encoding). Additivity suggests that alertness does not affect this process. Furthermore, when the first letter served as the warning stimulus, the improvement was the sum of the improvements due to alertness and encoding separately. This indicates that the processes of phasic alertness and encoding can proceed in parallel. (3) If phasic alertness did lead to an improvement in the sensory registration of the stimulus, then the presentation of a warning signal should result in a genuine improvement (that is, a decrease in errors as well as reaction time) in all tasks that require the processing of external signals. In many situations, however, the reduction in reaction time is accomplished at the expense of accuracy (Bernstein et al, 1973; Bertelson, 1967; Bertelson \& Tisseyre, 1968, 1969; Posner et al, 1973). 


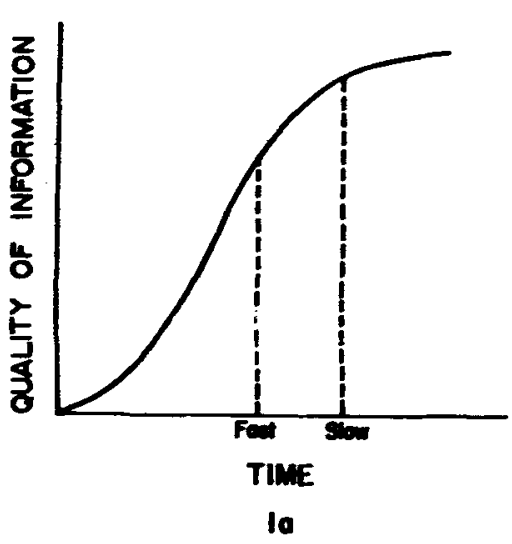

In order to evaluate the view that alertness acts mainly by increasing the rate of motor processes, it is necessary to specify the meaning of the term "motor." At the peripheral level, the term might be used to refer to processes which control the response after it has been initiated. Alertness probably does not affect this stage. Botwinick and Thompson (1966) have shown that foreperiod duration does not alter the time between the first signs of EMG and the actual response.

A more central definition of "motor" might include the processes intervening between the decision to respond and the initiation of the response. If this were the primary locus of the effect of alertness, then one would not expect alertness to alter the accuracy of S's responses, simply because this motor stage is assumed to follow S's decision. Both the speed-accuracy tradeoff found in some studies (see above) and the genuine improvement found in others (Fuster, 1958; Leavitt, 1969 ; Posner et al, 1973) argue against this stage as the locus for foreperiod effects.

The evidence against the sensory and motor explanations for phasic alertness effects supports (by elimination) the view that phasic alertness affects the operation of a central stage. Posner (1974; Posner et al, 1973) has proposed a theory in which such effects are assumed. This view assumes that information about the stimulus accumulates in a memory system at the same rate regardless of the level of alertness (see above). Phasic alertness is assumed to affect the time at which a later central decision mechanism consults the information accumulating in memory. The decision mechanism accepts the sensory information and initiates a response sooner when the organism is alert than when the organism is not alert. These two assumptions predict a speed-accuracy tradeoff when the signal is continuous because, by responding earlier, the decision mechanism responds to less accurate information (see Fig. 1a). A less obvious aspect of this theory is that under different stimulus conditions, alertness is expected to result in a genuine improvement in performance. When the signal is brief and weak, the information accumulating from stimulation will begin decaying soon after the stimulus is terminated. Under such stimulus conditions, phasic alertness may result in an improvement in both speed and accuracy because, by responding sooner, the
Fig. 1. Hypothetical buildup of information about a signal as a function of time. The signal is continuous in $1 \mathrm{a}$ and presented only briefly in 1b. Fast RTs may be associated with increased (1b) or reduced (1a) quality of information. Redrawn from Posner (1974). decision mechanism can respond to more accurate information (see Fig. 1b). This dual view clears up an important discrepancy in the foreperiod literature: Brief signals have been used in studies which found a genuine improvement (Fuster, 1958; Leavitt, 1969), while continuous signals have been used in studies which found a speed-accuracy tradeoff (Bernstein et al, 1973; Bertelson, 1967; Bertelson \& Tisseyre, 1968, 1969). Posner et al (1973) confirmed these predictions for brief and for continuous signals in several reaction time studies.

Most of the evidence supporting Posner's view comes from reaction time tasks (see Posner et al, 1973, for a discussion). It was felt that, if predictions from the model could be confirmed in a situation in which a rapid response was not required, the model would gain both credibility and generality. There are foreperiod data from several threshold studies (Howarth \& Triesman, 1958; Treisman, 1964; . Treisman \& Howarth, 1959) which did not require rapid responses. For our purposes, however, there are methodological problems with these studies. The present experiment was designed to minimize these problems. For example, changes in measured threshold may be due to a criterion change rather than an improved ability to detect the signal. To avoid this problem, a signal detection procedure was used to evaluate performance. Furthermore, in the threshold studies, the "warning signal" improved performance even when it occurred after the test stimulus. This suggests that the warning signal was providing information about the time at which the signal may have occurred. This type of temporal uncertainty was minimized by presenting a visual masking stimulus immediately after the time at which the test signal may have occurred. The present study used six foreperiods ranging between 0 and $1,000 \mathrm{msec}$ in order to obtain a detailed picture of the performance changes during this interval. In this signal detection paradigm (with a weak and brief visual signal), Posner's model predicts that detectability should improve until some optimal value, after which it should remain the same or deteriorate.

\section{METHOD}

Subjects

Two male and three female young adults served as paid Ss. Ss 
had normal hearing and normal or corrected vision. Two Ss had experience in signal detection, while the other three did not.

\section{Apparatus and Visual Display}

The experiment was controlled by a PDP-15 computer. Experiment Writer, a special compiler that interprets basic English command strings, was used to write the program that controlled the study (see Lewis, Osgood, \& Hebert, 1973, for a discussion). Signals and messages were displayed on a Hewlitt-Packard 1300 oscilloscope with a P11 phosphor.

An oval fixation point subtending approximately $30 \mathrm{~min}$ of visual angle remained on the scope throughout each block of trials. The visual signal, a symmetrical cross, was superimposed on the fixation point. Nine dots were used to construct the cross which subtended an angle of $1 \mathrm{deg} 42 \mathrm{~min}$. A rectangular mask composed of 35 dots was used to cover the area in which the signal was displayed. The characters $R 1$ and $R 2$, which prompted S's responses, were displayed on the same line $6 \mathrm{deg}$ to the right of fixation. The fixation point, signal, mask, and response cues were presented at low levels of brightness with the fixation point somewhat lower than the rest.

The experimental room was dimly illuminated by indirect lighting. The $S$ used a chinrest placed to assure a constant binocular viewing distance of about $9.5 \mathrm{in}$. The scope and chinrest were enclosed by a black wooden compartment that shielded both sides of the viewing area from glare.

The $\mathrm{S}$ wore earphones throughout the experiment. The auditory warning signal presented on five-sixths of the trials was a clearly audible $800-\mathrm{Hz}$ tone. The duration of the tone was $50 \mathrm{msec}$.

\section{Procedure}

A rating procedure that required a signal-no signal decision followed by a four-category confidence rating was employed. An equal number of six types of trials were run in mixed blocks: no warning, and 50-, 150-, 250-, 500-, and 1,000-m sec foreperiods. The visual signal (cross) was displayed on half of each of the six types of trials. The computer randomized the order of presentation for the six foreperiod conditions and for signal vs no signal trials in each foreperiod condition. Randomly selected delays of $2,000,3,000$, or $4,000 \mathrm{msec}$ between trials were presented with equal frequency preceding each trial type. A $370-\mathrm{msec}$ interval was added to the intertrial interval before trials with no warning.

The visual signal was displayed for $2 \mathrm{msec}$ and then allowed to decay until the mask covered the area. The length of the interval between signal onset and the mask onset was determined individually for each $S$ to yield approximately $75 \%$ accuracy. The mean interval for the five Ss was $38 \mathrm{msec}$, with a range between 32 and $52 \mathrm{msec}$. Once determined, the interval was not varied. The mask occurred on all trials and lasted for $200 \mathrm{msec}$. After a $500-\mathrm{msec}$ delay, the message R1 was displayed until S's first response. This response indicated the presence or absence of the signal and was followed by the message $R 2$, which was displayed until $\mathrm{S}$ indicated his confidence rating by making a second response.

Each $S$ was employed for five or more $1 \frac{1 / 2-h}{h}$ sessions within a

Table 1

$d_{a}$ for Each Subject in Each of the Foreperiod Conditions

\begin{tabular}{rrrrrrr}
\hline & \multicolumn{6}{c}{ Foreperiod } \\
\cline { 2 - 7 } $\mathrm{S}$ & 0 & 50 & 150 & 250 & 500 & 1000 \\
\hline 1 & .76 & 1.15 & 1.29 & 1.47 & 1.49 & 1.44 \\
2 & 1.53 & 1.79 & 1.75 & 1.61 & 2.08 & 1.54 \\
3 & 1.37 & 1.40 & 1.99 & 1.54 & 2.07 & 1.76 \\
4 & .91 & 1.15 & 1.46 & 2.14 & 2.33 & 2.01 \\
5 & 1.08 & 1.26 & 1.43 & 1.85 & 2.31 & 1.69 \\
$\bar{X}$ & 1.13 & 1.35 & 1.58 & 1.72 & 2.06 & 1.69 \\
\hline
\end{tabular}

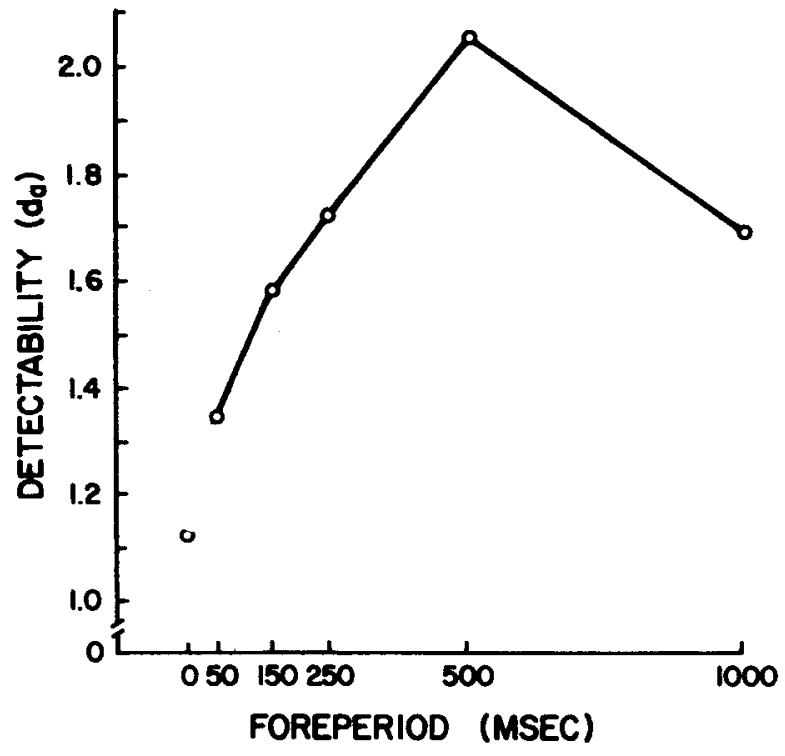

Fig. 2. Discriminability $\left(d_{a}\right)$ as a function of foreperiod duration.

period of 2 weeks. The first day was devoted to familiarizing $S$ with the experimental procedure and to determining the mask delay. One $\mathrm{S}$ required 2 days of practice. Each $\mathrm{S}$ completed 4 days of experimental trials. Six teen blocks of 36 trials each were presented each day. Two Ss were run in extra experimental sessions because of equipment failure.

On each experimental day, $S$ was dark adapted for $5 \mathrm{~min}$ and then received two 36-trial practice (warm-up) blocks. The first block used a 102-msec delay between the stimulus onset and mask onset, while the second used the interval that had been previously determined for the particular $\mathrm{S}$. The $\mathrm{Ss}$ then received eight blocks of trials, a 5-min rest session, and eight additional blocks of trials.

\section{Analysis}

Over the four experimental sessions, each S contributed 2,304 responses, 384 for each of the six warning intervals, with 192 from signal and 192 from no signal trials in each condition. Discriminability $\left(d^{\prime}\right)$ values were determined for each $\mathrm{S}$ for each of the six warning intervals. ROC curves were fitted by a least squares method. The $d_{s}$ value was determined for each ROC curve by the intersection of the ROC with the negative diagonal. Since $d_{s}$ is a biased estimate of $d^{\prime}$ when the slope of the ROC curve is not equal to one, a corrected estimate of $d_{s}\left(d_{2}\right)$ was calculated.

\section{RESULTS AND DISCUSSION}

The $d_{a}$ values for each $S$ are presented in Table 1. A one-way within-Ss analysis of variance was used to test for differences in $d_{a}$ for the six foreperiods. The foreperiods' main effect was significant $[F(5,20)=$ $8.983, \mathrm{p}<.001]$. Discriminability increased across foreperiods until the $500-\mathrm{msec}$ interval, and then decreased (see Fig. 2). The 500-msec foreperiod proved to be the optimal foreperiod for all five Ss. All five Ss showed a decrease in $d_{a}$ between the 500- and 1,000-msec intervals (see Table 1).

It is important to demonstrate that the improvement in performance with increasing foreperiods is not due to peripheral factors. It might be argued, for example, that 
the warning signal results in a peripheral adjustment of the visual system such as a saccade to the fixation point or improved binocular convergence. The fact that all five Ss' performance was improved by the 50 -msec warning is evidence against this view. The interval between the tone onset and the signal onset is $100 \mathrm{msec}$ (tone duration is $50 \mathrm{msec}$ and the interval is $50 \mathrm{msec}$ ), which is too short for either type of adjustment (see Robinson, 1968). While a peripheral explanation could still be applied to longer foreperiods, it is more parsimonious to assume that the same process is operating for all foreperiods.

It may be asked whether temporal uncertainty is a factor in the data. This is a complicated question. There are several kinds of temporal uncertainty. One type which has been thoroughly studied in signal detection tasks (e.g., Egan, Greenberg, \& Schulman, 1961) is related to the size of the interval in which the signal may occur. We eliminated this type of uncertainty by presenting the masking stimulus immediately after the occurrence or nonoccurrence of the signal. Under these conditions, $\mathrm{S}$ had no uncertainty about when the signal may have occurred. Temporal uncertainty may also be related to when the signal will occur. This type of uncertainty is related to the size and the variability of the foreperiods used. When the foreperiod is constant for a block of trials, S's uncertainty about when the signal will occur is related to the size of the foreperiod. On the other hand, when the foreperiod varies randomly from trial to trial, uncertainty will be related to the variance and type of distribution of foreperiods. Although some RT studies have shown differences between foreperiod functions obtained with constant and variable blocks (Klemmer, 1956; Drazin, 1961), more recent investigations have shown similar functions for the two conditions (Bertelson \& Tisseyre, 1968; Sanders, 1972). One difference between these two sets of studies is that those which found differences for constant and variable blocks used a simple RT task, while those finding similar functions used choice RT. This is an important distinction. Ss are more apt to anticipate the occurrence of the stimulus in simple RT than in choice RT tasks. Since our interest is in processing of the signal, the choice tasks which necessitate such processing are more relevant. Since the choice studies found similar foreperiod functions for the constant and variable paradigms, it is reasonable to conclude that either temporal uncertainty is not a significant factor in these studies or that the temporal uncertainty is similar in these two conditions.

Our choice of a variable foreperiod was based on the finding that variable foreperiods lead to less noisy data than constant foreperiods (Bertelson \& Tisseyre, 1968), presumably because of counterbalancing difficulties in the constant block technique. Although the exact time course of alertness changes which follow a warning signal may be influenced by the range and variability of the foreperiods used, we feel that the processes underlying these changes are the same whether the foreperiod is constant or varied randomly between trials.

The effect of foreperiod on $\mathrm{d}^{\prime}$ found in this study, together with the material discussed in the introduction, indicate that the locus of the phasic alertness effect is central in nature. Posner's view of the form of these effects states that phasic alertness affects the time at which the decision mechanism consults the memory system, where sensory information accumulates at a fixed rate. This view predicts a speed-accuracy tradeoff when the signal is continuous. By responding sooner, the decision mechanism will have less accurate information. For brief and weak signals, however, the quality of information in memory will be decreasing soon after termination of the stimulus. By responding sooner, the decision mechanism may have more accurate information, and therefore a genuine improvement in performance may occur. Reaction time evidence (as discussed in Posner et al, 1973) supports this theory. In the present study, a signal detection task was used to show that the predictions for brief and weak signals are confirmed even when no speeded response is required.

\section{REFERENCES}

Bernstein, I. H., Chu, P. K., Briggs, P., \& Schurman, D. L. Stimulus intensity and foreperiod effects in intersensory facilitation. Quarterly Journal of Experimental Psychology, $1973,25,171-181$.

Bertelson, P. The time course of preparation. Quarterly Journal of Experimental Psychology, 1967, 19, 273-279.

Bertelson, P., \& Tisseyre, F. The time course of preparation with regular and irregular foreperiods. Quarterly Journal of Experimental Psychology, 1968, 20, 297-300.

Bertelson, P., \& Tisseyre, F. The time course of preparation: Confirmatory results with visual and auditory warning signals. Acta Psychologica, 1969, 30, 145-154.

Botwinick, J. Joint effects of stimulus intensity and preparatory interval on simple auditory reaction time. Journal of Experimental Psychology, 1969, 80, 348-352.

Botwinick, J., \& Storand $t, \dot{M}$. Sensation and set in reaction time. Perceptual \& Motor Skills, 1972, 34, 103-106.

Botwinick, J., \& Thompson, L. W. Premotor and motor components of reaction time. Joumal of Experimental Psychology, 1966, 71, 9-15.

Drazin, D. H. Effects of foreperiod, foreperiod variability and probability of stimulus occurrence on simple reaction time. Journal of Experimental Psychology, 1961, 62, 43-50.

Egan, J. P., Greenberg, G. Z., \& Schulman, A. I, Interval of time uncertainty in auditory detection. Journal of the Acoustical Society of America, 1961, 33, 771-778.

Fuster, J. M. Effect of stimulation of brain stem on tachistoscopic perception. Science, 1958, 127, 150.

Howarth, C. I., \& Treisman, M. The effect of warning interval on the electric phosphene and auditory thresholds. Quarterly Journal of Experimental Psychology, 1958, 10, 130-141.

Klemmer, E. T. Time uncertainty in simple reaction time. Journal of Experimental Psychology, 1956, 51, 179-184.

Lansing, R. W., Schwartz, E., \& Lindsley, D. B. Reaction time and EEG activation under alerted and non-alerted conditions. Journal of Experimental Psychology, 1959, 58, 1-7.

Leavitt, F. Accuracy of report and central readiness. Journal of Experimental Psy chology, 1969, 81, 542-546.

Lewis, J. L., Osgood, G. W. \& Hebert, J. J. Pleiades: Real-time-sharing control in the behavioral science laboratory. Behavior Research Methods \& Instrumentation, 1973, 5, 365-370.

Posner, M. I. The psychobiology of attention. In C. Blakemore and M. Gazzaniga (Eds.), Handbook of psychobiology. New York: Academic Press, 1974.

Posner, M. I., \& Boies, S. J. Components of attention. Psychological Review, 1971, 78, 391-408.

Posner, M. I., Klein, R. M., Summers, J. J., \& Buggie, S. E. On the selection of signals. Memory \& Cognition, 1973, 1, 2-12.

Raab, D., Fehrer, E., \& Hershenson, M. Visual RT and the Broca-sulzer phenomenon. Journal of Experimental Psychology, 1961, 61, 193-199. 
Rebert, C. S., \& Tecce, J. J. A summary of CNV and reaction time. In W. C. Callum and J. R. Knott (Eds.), Event related slow potentials of the brain and their relation to behavior. Amsterdam: Elsevier, in press.

Robinson, D. A. The oculomotor control system: A review. Proceedings of the IEEE, 1968, 56, 1032-1049.

Sanders, A. F. Foreperiod duration and the time course of preparation. Acta Psychologica, 1972, 36, 60-71.

Sternberg, S. The discovery of processing stages: Extensions of Donders' method. In W. G. Koster (Ed.), Attention and performance II. Amsterdam: North-Holland, 1969.

Tecce, J. J. Contingent negative variation (CNV) and psychological processes in man. Psychological Bulletin, 1972, 77, 73-108.

Treisman. M. The effect of one stimulus on the threshold for another: An application of signal detectability theory. British Journal of Psychology, 1964, 18, 15-35.

Treisman, M., \& Howarth, C. I. Changes in threshold level produced by a signal preceding or following the threshold stimulus. Quarterly Journal of Experimental Psychology, $1959,11,129-142$.

Webb, R. A., \& Obrist, P. A. The physiological concomitants of reaction time performance as a function of preparatory interval series. Psychophy siology, 1970, 6, 389-403.

Wickelgren, W. A. Trace resistance and the decay of long-term memory. Journal of Mathematical Psychology, 1972, 9, 418-455.

\section{NOTES}

1. We will limit our consideration to studies which presented the warning and reaction signals to different modalities. Intramodal effects that are not related to alertness may be obtained when both signals are presented to the same modality.

2. This exclusion is not arbitrary. By extremely weak stimuli we refer to those which might not be detected on every trial. With such stimuli, Ss may employ guessing, anticipation, or other strategies that may be influenced by alertness. See Botwinick (1969) for an example of additivity between intensity and foreperiod duration with suprathreshold stimuli, but an interaction when subthreshold stimuli are considered. By extremely intense stimuli we refer to those which might be painful or annoying. They may have motivational consequences which may be affected by alertness.

3. A constant (k) was determined from the linear regression of log slope on $\mathrm{d}_{\mathrm{s}}$ for the six experimental conditions (log slope $=$ $0+k_{s}$, which assumes $\log$ slope $=0$ at $d_{s}=0$ ). Each $d_{s}$ was converted to the unbiased $d_{2}$ measure using the equation $d_{a}=d_{s} / 2\left(1+e^{\left.-k d_{s}\right)}\right.$. See Wickelgren (1972) for a discussion of this procedure.

(Received for publication September 17, 1973; revision received October 23,1973 .) 